\title{
Religion and the Stigma of Suicide: A Quantitative Analysis Using Nationwide Survey Data from Hungary
}

\author{
Ferenc Moksony * and Rita Hegedús
}

Citation: Moksony, Ferenc, and Rita Hegedús. 2021. Religion and the Stigma of Suicide: A Quantitative Analysis Using Nationwide Survey Data from Hungary. Religions 12: 908. https://doi.org/10.3390/rel12110908

Academic Editor: Curtis Lehmann

Received: 27 August 2021

Accepted: 13 October 2021

Published: 21 October 2021

Publisher's Note: MDPI stays neutral with regard to jurisdictional claims in published maps and institutional affiliations.

Copyright: (c) 2021 by the authors. Licensee MDPI, Basel, Switzerland. This article is an open access article distributed under the terms and conditions of the Creative Commons Attribution (CC BY) license (https:/ / creativecommons.org/licenses/by/ $4.0 /)$.
Institute of Communication and Sociology, Corvinus University of Budapest, Fővám tér 8, 1093 Budapest, Hungary; rita.hegedus@uni-corvinus.hu

* Correspondence: fmokson@gmail.com

\begin{abstract}
Objective: To examine the effect of religion on negative attitudes and beliefs about suicide. Methods: We use data from a large nationwide survey conducted in Hungary covering more than 3000 individuals. Suicide-related stigmas are captured with three Likert-type measures that we combine into an overall indicator. Religion is measured by denomination (Catholic vs. Protestant) and church attendance (at least weekly vs. never or less than weekly). We employ logistic regression and the SPSS statistical software. Results: People attending religious services frequently have greater odds of stigmatizing self-killing than those reporting no or infrequent attendance. Compared to Protestants, Catholics are significantly less condemning of suicide. The two measures of religion also work in tandem, with denomination modifying the impact of church attendance. In particular, while church attendance strongly increases the odds of negative attitudes among Catholics, it has practically no effect among Protestants. Discussion and Conclusions: The results presented are in keeping with our expectations and suggest that a social climate that stigmatizes suicide without providing for people a strong community network that pressures individuals toward conforming to fundamental moral principles can be especially harmful for mental health.
\end{abstract}

Keywords: suicide; stigma; religion; denominations; deviant behavior

This paper addresses the intersection of three topical areas that have, thus far, received relatively little scholarly attention. While the literature on religion and suicide is vast (for recent reviews, see Lawrence et al. 2016; Gearing and Alonzo 2018), as is the literature on the effect of stigma on various mental health problems, including self-killing (e.g., Sudak et al. 2008; Clement et al. 2014; Schomerus et al. 2014; Bernardo and Pinna 2017; Goodwill and Zhu 2020), only a handful of studies have looked at all three aspects simultaneously and examined how negative religious stereotypes affect the risk of self-killing (e.g., van den Brink et al. 2018; Caplan 2019; Mason 2021). The research reported in this article seeks to redress this imbalance of attention by using data from a nationwide survey conducted in Hungary. In more substantive terms, our work intends to contribute to the line of theoretical and empirical inquiries that focus on the relative importance of social and cultural factors in explaining religious differences in suicide. Mainly due to the overarching influence of Émile Durkheim's legacy, studies in this field (e.g., Pescosolido 1994; Stack and Kposowa 2011) have commonly emphasized the role that social integration plays in saving individuals from killing themselves and have regarded the norms, values, and general world views that are characteristic of various denominations as only of secondary relevance. Building on our earlier research on this topic (Hegedús 2019), we aim to provide a more balanced and nuanced conception of this issue, paying due attention to the cultural aspects of religions and, what is at least as crucial, emphasizing their interaction with embeddedness in the church community.

\section{Background and Previous Research}

Research on religion and suicide dates back to the 19th century and has been greatly inspired by Émile Durkheim's seminal book, published in 1897 (Durkheim [1897] 1951). 
Durkheim's central concept was social integration, which he also relied on to explain why Protestants are more prone than Catholics to take their life. In his view, the main causal factor was not that various religions have different norms, values, and beliefs but rather that they have different degrees of social cohesion. As he wrote, "The details of dogmas and rites are secondary. The essential thing is that they be capable of supporting a sufficiently intense collective life" (Durkheim [1897] 1951, p. 170).

Later research largely followed Durkheim in emphasizing the importance of people's attachment to the church community, while downplaying the role of cultural factors. Social and emotional support deriving from membership in a dense network of fellow affiliates was generally regarded as the main causal force that keeps believers from taking their life. The chief advocate of this view was Bernice Pescosolido who maintained that "[t]he protective power of religion depends on the ability of religious networks to provide a source of support on which individuals can draw during difficult times" (Pescosolido 1994, p. 272). While Pescosolido attempted to translate Durkheim's ideas into the language of modern network analysis, Stack and Kposowa (2011) tried to refine those ideas by disentangling the various aspects of the effect of integration, distinguishing, among other things, the impact of the moral community, which affects co-religionists and non-co-religionists alike, from that of the religious network, which is mainly confined to members of the same religion (Stack and Kposowa 2011, p. 294). Although this work has substantially advanced Durkheim's legacy, it has still largely remained within the confines of the traditional integration perspective.

Long as Durkheim's shadow has been, however, some recent studies departed from the dominant paradigm and provided evidence suggesting that norms, values, and broader world views peculiar to various denominations may crucially contribute to religious differences in suicide and other mental health problems. Schwadel and Falci (2012), for example, looked at the joint impact of church attendance and religious traditions and found a significant interaction effect, with frequent attendance decreasing mental health for evangelical Protestants but not for members of other denominations. This result made sense given that the values and beliefs prevailing among evangelical Protestants tend to give rise, as the authors noted, to "a lack of control and a sense of helplessness", thus diminishing people's "ability to cope with stress" (p. 23). Our latest research (Moksony and Hegedús 2019) also pointed in this direction, showing, among other things, that attachment to the church community has opposite effects for Catholics and Protestants. While in the first group the risk of suicide declined with increasing levels of attendance, in the second, strong embeddedness in the network of fellow affiliates made believers more, rather than less, likely to take their life. This finding was understandable against the backdrop of the broader cultural differences between the two religions, with Protestants typically having a less cheerful view of the world and a more anxious stance to life (see Greeley 1989; Torgler and Schaltegger 2014; Becker and Woessmann 2011, 2015).

Studies such as those just mentioned have, overall, made a rather compelling case for the necessity of taking cultural factors seriously into account when explaining religious variations in self-killing. While these factors obviously are quite diverse and numerous, stereotyped social attitudes and beliefs about suicide are certainly among the most crucial. Very often, these attitudes and beliefs are negative, such as when taking one's life is seen as a sign of cowardice, in which case we have what are generally called stigmas. ${ }^{1}$

Stigmas are of different kinds and may have different effects. One distinction is that between experienced and anticipated stigma, the former referring to actual encounters with stigmatizing attitudes and behaviors (Simonsen et al. 2019) and the latter to expectations of stigma experiences happening in the future (Kane et al. 2019); for a cross-national survey of these two forms of stigma, see Thornicroft et al. (2009). Another distinction, which is perhaps of more immediate relevance for our study, is that between public and self-stigma, the former referring to negative attitudes and beliefs prevailing in the population at large and the latter to the internalization of those attitudes and beliefs by the individuals who possess the stigmatized characteristics (Corrigan and Rao 2012; Coleman et al. 2017). ${ }^{2}$ 
This second distinction is especially relevant for the present article because our study is based on data from a large-scale nationwide public opinion survey, which is mainly suitable to capture public stigmas, with self-stigmas generally being more accessible to other forms of data collection, such as interviews. (On the issue of self-stigma and mental health problems, including suicide, see e.g., Rüsch et al. 2010; Corrigan and Rao 2012; Rimkeviciene et al. 2015).

The impact of stigma, whether public or internalized, may differ depending on the particular underlying causal mechanism (see Figure 1). On the one hand, negative attitudes may act as normative constraints, keeping people from engaging in behaviors that are deemed socially undesirable. Moral objections to suicide, for instance, have been shown to exert such a restraining effect (Lizardi et al. 2008; van den Brink et al. 2018). On the other hand, stigmas may also have deleterious consequences, potentially triggering, rather than preventing, deviant acts of various kinds. One way this can happen is that negative stereotyped beliefs may deter those in need from seeking help (Corrigan 2004; Schomerus et al. 2010; Clement et al. 2014; Reynders et al. 2015). Another way in which stigmas might increase the risk of mental health problems, including suicide, is that negative attitudes frequently contain causal attributions that blame sufferers for their condition (Rüsch et al. 2010; Caplan 2019).

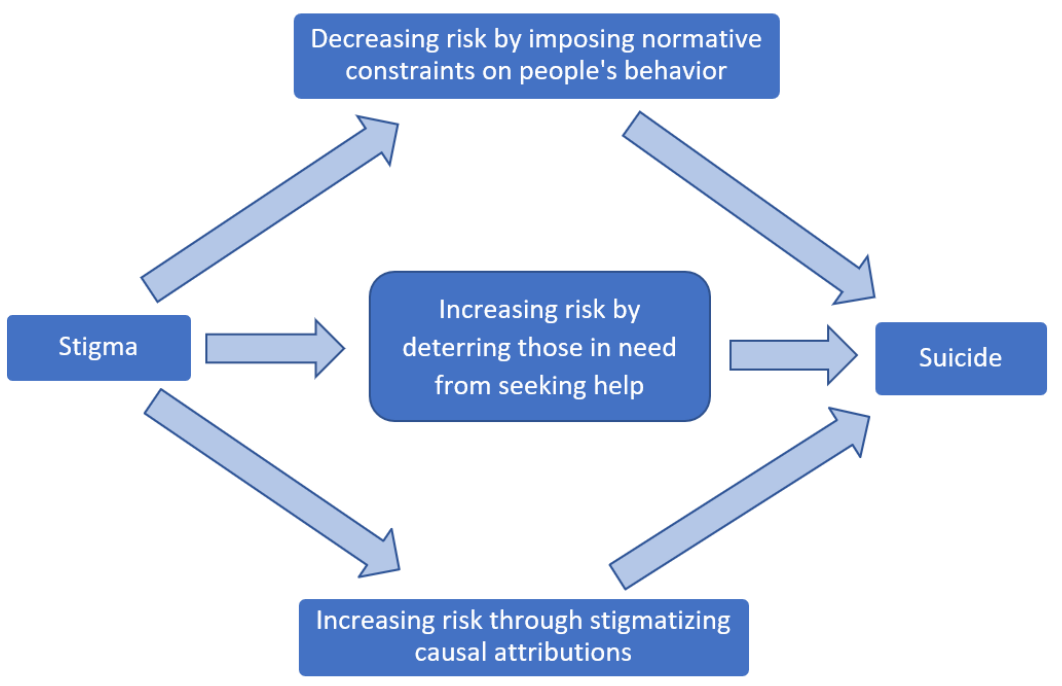

Figure 1. Possible causal mechanisms underlying the effect of stigma on suicide.

The harmful effect of stigma has been demonstrated in a cross-sectional study by Schomerus et al. (2014), where low levels of social acceptance of persons with mental health problems were associated with high suicide rates across 25 European countries. Some results from an earlier study of ours (Moksony 1998) also pointed in this direction, showing that certain negative attitudes toward suicide are more prevalent in regions with high rates of this form of deviant behavior. Comparing Hungarians living in regions with highly different suicide rates, we found that those from the southeast, where suicide traditionally is more common, were more likely to say they would strongly object to the suicide of a close relative being reported in the media. Additionally, they were more likely to regard this form of deviant behavior as a sign of cowardice, although this difference was statistically significant in rural areas only.

How do the various causal mechanisms outlined above bear on the relationship between religion and the stigmatization of suicide? Based on our earlier research (Moksony and Hegedús 2019) as well as some recent studies on the multifaceted role that interpersonal ties play in the causation of suicide and other forms of deviant behavior (e.g., Schwadel and Falci 2012; Abrutyn and Mueller 2014, 2016; Mueller et al. 2015; Mueller and Abrutyn 2016), we expect that in different religious cultures, as represented by different denominations, negative attitudes operate through different causal channels. In particular, among 
Protestants, they mainly work as stigmatizing causal attributions that attack core personality characteristics and challenge the self as a whole, rather than specific behaviors. In addition, they largely function as a sort of personal burden and, thus, their influence is less dependent on interaction with fellow affiliates. Among Catholics, in contrast, negative attitudes work more as normative constraints imposed on people's actions, with believers faithfully accepting and following the moral principles prevailing in the church community. This implies that for stigmas to fully exert their effect, deeper social embeddedness and stronger ties to co-religionists are now needed.

The distinction made by psychologists Helen Block Lewis and June P Tangney between shame and guilt might help understand how negative attitudes work differently for Protestants and Catholics. ${ }^{3}$ While shame, according to Lewis, is "directly about the self ...., [i]n guilt, the self is not the central object of evaluation, but rather the thing done or undone is the focus" (Lewis 1971, quoted by Tangney et al. 1996, p. 1257; emphasis in the original). Thus, although negative feelings are implicated in both, in guilt, those feelings pertain to specific deeds or events, whereas in shame, they are more pervasive and attack one's whole identity (Dearing et al. 2005). As a result, shame tends to be more destructive than guilt and may increase the risk of various mental health problems more, including suicide.

The importance of the shame-guilt distinction lies in the fact that it provides a conceptual framework that helps understand how apparently similar negative attitudes might have different psychological and mental health effects depending on whether they categorically condemn one's entire personality or work more as normative constraints imposed on one's behavior. This distinction, thus, allows us to go beyond a simplified conception of stigmas and enables a more nuanced approach to the phenomenon of stigmatization.

How does the shame-guilt distinction relate to the different ways negative attitudes exert their impact in various religious cultures? Among Catholics, those attitudes work more like guilt and, thus, they are less destructive and are more "likely to motivate the individual in a positive direction" (Dearing et al. 2005, p. 1393). Among Protestants, in contrast, negative attitudes are more similar to shame in that they attack the core of one's self and call into question one's whole identity. This difference may also partly explain the observation made by Durkheim and corroborated by a number of later research, including ours (Moksony and Hegedús 2019), that Protestants are more prone than Catholics to take their life.

\section{Data and Methods}

The data used in our research came from the 1994 wave of a large nationwide survey called the Hungarian Panel Study. Repeated yearly from 1992 to 1997, this omnibus survey was based on a representative sample of the Hungarian population, and its 1994 wave covered 3766 individuals. Using financial support received from the Hungarian Scientific Research Fund, we appended our attitude questions to the core body of the questionnaire. At the time of data collection, there was no need for an ethical approval.

While fairly old, the data set used in our study had several advantages that made it especially suitable for our purposes. First, it contained rich information on both respondents' religiousness and their attitudes about suicide, thus allowing us to examine the relationship between the two in sufficient detail. Second, the sample was not only considerably larger than those commonly found in the literature but also had the benefit that it represented the general population, while the data used in other studies on this topic often pertain to more specialized groups, such as depressed patients or college students, which may restrict the external validity of the results. ${ }^{4}$

We employed three Likert-type measures with five levels each to capture negative attitudes and beliefs about suicide. The first asked respondents if they agree with the statement that suicide is a sign of cowardice. The second asked them if they would object to the suicide of a close relative being reported in the media. Finally, the third asked them if they think suicidal individuals are completely different from the rest of the population. Due to their highly skewed distributions, we combined these three measures into a single 
dichotomous variable that distinguished respondents choosing the most stigmatizing response category from those selecting more tolerant options.

The main independent variable was religion, which we captured with two measures. The first was church attendance, which separated those who said they attend religious services at least once a week from those who reported no or infrequent attendance. The second was denomination, which was based on asking people about the faith they were christened into and distinguished the two religions prevailing in Hungary, Catholics and Protestants. ${ }^{5}$ (These two groups accounted for 95 percent of our sample; the remaining 5 percent, which contained people of other faiths and those of no religion, were excluded from the analysis.)

Given the binary nature of the dependent variable, we used logistic regression and the SPSS statistical software to examine the effect of religion on suicide-related negative attitudes.

\section{Results}

We first looked at the additive effect of the two measures of religion, each entered in the regression as $0-1$ dummy variables. On the church attendance dummy, people attending religious services at least once a week were coded 1 , whereas those reporting no or infrequent attendance were coded 0 . On the denominations dummy, we coded Catholics 1 and Protestants 0 . The dependent variable was also dichotomous, with respondents choosing the most stigmatizing option coded 1 and those selecting milder alternatives coded 0 . Results are shown in Table 1, where logistic regression coefficients and their antilogarithms are reported. Given the use of $0-1$ dummy coding, the antilogarithms of the coefficients can directly be interpreted as odds ratios.

Table 1. Additive effect of denomination and church attendance on negative attitudes about suicide. Logistic regression results.

\begin{tabular}{ccc}
\hline Variables & Regression Coefficient & Odds Ratio \\
\hline Denomination $^{\mathrm{a}}$ & $-0.206^{*}$ & 0.814 \\
Church attendance $^{\mathrm{b}}$ & $0.403^{* *}$ & 1.497 \\
Constant $^{*}$ & 0.838 & 2.312 \\
\hline
\end{tabular}

${ }^{*} p<0.05 ;{ }^{* *} p<0.01{ }^{a}$ reference: Protestant; ${ }^{b}$ reference: no or infrequent attendance.

As can be seen, Catholics have significantly less stigmatizing attitudes, with the odds of selecting the most negative response category being 18.6 percent smaller among them than among Protestants. The effect of church attendance is also significant, with people attending religious services at least weekly being more condemning of self-killing than those reporting no or infrequent attendance. In particular, as shown by the odds ratio, the odds of selecting the most negative response category was about 50 percent greater in the first group than in the second.

Earlier, we made a distinction between Protestants and Catholics in terms of how negative attitudes and feelings about suicide might exert their impact. One key difference mentioned was that while for Protestants, the influence of those attitudes and beliefs is less dependent on interaction with fellow affiliates, for Catholics, a strong attachment to the church community is typically required for stigmas to have their full effect. This suggests that the frequency of church attendance, which we can use as an indicator of the degree of embeddedness in the network of co-religionists, differentially affects the two denominations: it strongly increases the chance of stigmatization among Catholics but has only small, or even no, effect among Protestants.

To check this expectation, we ran separate logistic regressions for the two denominations using church attendance as an independent variable. The results, shown in Table 2, support our prediction. For Catholics, the coefficient for the church attendance dummy is positive and statistically significant, indicating that in this group, strong attachment to the church community does indeed increase stigmatization. As can be seen from the odds ratio 
(1.607), the odds of selecting the most negative response category is about 60 percent greater among those attending religious services at least weekly than among those reporting no or infrequent attendance. The picture is quite different for Protestants, where church attendance is practically of no relevance (the odds ratio is very close to 1 , the value indicating no effect).

Table 2. Interaction effect of denomination and church attendance on negative attitudes about suicide. Logistic regression results.

\begin{tabular}{ccccc}
\hline \multirow{2}{*}{ Variables } & \multicolumn{2}{c}{ Catholics } & \multicolumn{2}{c}{ Protestants } \\
\cline { 2 - 5 } & Coefficient & Odds Ratio & Coefficient & Odds Ratio \\
\hline $\begin{array}{c}\text { Church } \\
\text { attendance }\end{array}$ & $0.474^{*}$ & 1.607 & 0.097 & 1.102 \\
Constant & 0.624 & 1.867 & 0.859 & 2.360 \\
\hline${ }^{*} p<0.01 .{ }^{a}$ reference: no or infrequent attendance. &
\end{tabular}

\section{Discussion and Conclusions}

This paper reported results from a study that examined a topic that has thus far received relatively little attention. While much research has been devoted to the impact of religion on the risk of suicide, and considerable work has been conducted on how stigmatization affects those suffering from mental health problems of various kinds, the intersection of religion, stigma, and suicide has seldom been the focus of empirical inquiry, especially that of quantitative nature. Our aim was to partially fill this gap by using data from a large-scale survey that included information both on religious behavior and suiciderelated negative attitudes and has covered the entire general population of Hungary, rather than being confined to specialized groups, such as patients or college students.

All in all, the findings presented have shown that religion plays a significant role in shaping attitudes about suicide. Attachment to the church community has turned out to be one important factor, with individuals attending religious services at least weekly being much more condemning of this form of deviance than those reporting no or infrequent attendance. Another factor of great relevance was denomination, with Catholics exhibiting significantly less stigmatizing attitudes than Protestants. Finally, we also found the two measures of religion to work in tandem, with denomination modifying the impact that embeddedness in the religious community has on people's views and beliefs about suicide. In keeping with our expectations, church attendance significantly increased the odds of negative attitudes for Catholics, while it had practically no effect for Protestants.

This interaction effect between denomination and church attendance gains additional weight when viewed against the backdrop of the traditionally higher suicide rate for Protestants (Durkheim [1897] 1951; Becker and Woessmann 2018; Moksony and Hegedús 2019). Taken together, these two results suggest that a social climate that stigmatizes suicide without providing for people a strong community network that pressures individuals toward conforming to fundamental moral principles can be especially harmful for mental health. ${ }^{6}$

\subsection{Potential Avenues for Intervention}

Although our work is mainly sociological in nature, the findings presented in this article also have implications for clinical practice and prevention efforts. From earlier studies (e.g., Stangl et al. 2019; Stuber et al. 2008) we know that people at risk are, in their fear of being stigmatized, more likely to avoid contacts with their broader social environment, which, in turn, may further weaken their abilities to seek help, thus diminishing the chances of successful intervention. Our results also point in this direction, highlighting the importance of supportive social relationships and emphasizing that in order for normative regulation not to be destructive, it should be embedded in a living network of ties among fellow affiliates. Another suggestion that we can make based on our work and that also seems important for prevention is that when formulating negative moral judgements, 
church communities should focus on the behavior to be avoided, rather than condemning one's whole personality.

\subsection{Limitations}

No research, of course, can ever be complete, and ours is no exception. One limitation of our study is its focus on Western religions. Broadening the scope of the analysis to cover non-Western religions, such as Islam or Buddhism, would permit us to check the generalizability of our findings. Another factor that restricts the strength of our conclusions is that the data used in our research were rather old. Repeating the analysis with more recent data would certainly add to the credibility of the results presented in this article. Finally, while our study was confined to attitudes toward suicide, future investigations should also include suicidal behavior itself, which would allow a more direct analysis of the causal mechanisms underlying the relationship between religious stigma and suicide.

Author Contributions: The original empirical research on which the paper is based was conducted by F.M. The present study is the joint product of the two authors (F.M. and R.H.), they have participated equally in conceptualization, analysis, and writing the article. All authors have read and agreed to the published version of the manuscript.

Funding: The original empirical research on which the paper is based was funded by the Hungarian Scientific Research Fund, grant no.: F6733.

Institutional Review Board Statement: Institutional Review Board Statement was not required at the time the original empirical research was conducted.

Informed Consent Statement: Given the type of data collection (questionnaire survey), informed consent statement was not required.

Data Availability Statement: The data set on which the study reported in this article was based has been archived by Tárki and can be found at https://adatbank.tarki.hu/en/ (accessed on 19 October 2021).

Conflicts of Interest: The authors declare no conflict of interest.

\section{Notes}

1 The APA Dictionary of Psychology, for example, defines stigma as a "negative social attitude attached to a characteristic of an individual that may be regarded as a mental, physical, or social deficiency" (https://dictionary.apa.org/stigma, accessed 28 July 2021). The term sometimes is interpreted more broadly, covering not only negative attitudes but also various forms of discriminative behavior (Thornicroft et al. 2009).

2 Separating public from self-stigma is not always easy, though, since the two are mutually related to each other. This mutual relatedness issue essentially plagues the whole field of suicide research, such as when trying to separate physical from mental health symptoms (see Costanza et al. 2020).

3 We realized the bearing of the shame-guilt distinction on the different ways negative attitudes work for Catholics and Protestants while reading a paper by Teodóra Tomcsányi (Tomcsányi 2003), so we owe an indirect debt to her in this respect. It should also be noted that we use the shame-guilt distinction as a heuristic device and will, therefore, not go into the intricacies of this issue.

4 For a good overview of the kind of samples used in the literature on stigma, religion, and suicide, see Table 1 in van den Brink et al. (2018).

5 "Protestant", actually, is an umbrella term that covers two groups, the Reformed Church and the Lutheran Church. These two groups made up 23.4 and 2.6 percent of our sample, respectively, Catholics representing the largest share with 68.7 percent.

6 While a direct empirical test of this idea is yet to be done, our earlier analysis of data from the European Values Study has already shown that people in Hungary are generally rather condemning of suicide, while at the same time having a fairly high risk for this form of deviant behavior (Hegedús 2019).

\section{References}

Abrutyn, Seth, and Anna S. Mueller. 2014. Are suicidal behaviors contagious in adolescence? Using longitudinal data to examine suicide suggestion. American Sociological Review 79: 211-27. [CrossRef] [PubMed]

Abrutyn, Seth, and Anna S. Mueller. 2016. When too much integration and regulation hurts: Reenvisioning Durkheim's altruistic suicide. Society and Mental Health 6: 56-71. [CrossRef] 
Becker, Sascha O., and Ludger Woessmann. 2011. Knocking on Heaven's Door? Protestantism and Suicide. Warwick Economic Research Papers, No. 966. Coventry: University of Warwick.

Becker, Sascha O., and Ludger Woessmann. 2015. Social Cohesion, Religious Beliefs, and the Effect of Protestantism on Suicide. CESIFO Working Paper No. 5288. München: ifo Institute.

Becker, Sascha O., and Ludger Woessmann. 2018. Social cohesion, religious beliefs, and the effect of Protestantism on suicide. Review of Economics and Statistics 100: 377-91. [CrossRef]

Bernardo, Carpiniello, and Federica Pinna. 2017. The Reciprocal Relationship between Suicidality and Stigma. Frontiers in Psychiatry 8: 35. [CrossRef]

Caplan, Susan. 2019. Intersection of Cultural and Religious Beliefs About Mental Health: Latinos in the Faith-Based Setting. Hispanic Health Care International 17: 4-10. [CrossRef]

Clement, Sarah, Oliver Schauman, Tanya Graham, F. Maggioni, Sara Evans-Lacko, Nikita Bezborodovs, Craig Morgan, Nicolas Rüsch, June S. L. Brown, and Graham Thornicroft. 2014. What is the impact of mental health-related stigma on help-seeking? A systematic review of quantitative and qualitative studies. Psychological Medicine 45: 11-27. [CrossRef]

Coleman, Sarah, Oliver Schauman, Tanya Graham, F Maggioni, Sara Evans-Lacko, Craig Morgan, Nicolas Rüsch, June S.L. Brown, and Graham Thornicroft. 2017. Stigma-related barriers and facilitators to help seeking for mental health issues in the armed forces: A systematic review and thematic synthesis of qualitative literature. Psychological Medicine 47: 1-13. [CrossRef]

Corrigan, Patrick. 2004. How stigma interferes with mental health care. American Psychologist 59: 614-25. [CrossRef]

Corrigan, Patrick, and Deepa Rao. 2012. On the Self-Stigma of Mental Illness: Stages, Disclosure, and Strategies for Change. Canadian Journal of Psychiatry 57: 464-69. [CrossRef] [PubMed]

Costanza, Alessandra, Andrea Amerio, Michalina Radomska, Julia Ambrosetti, Sarah Di Marco, Massimo Prelati, Andrea Aguglia, Gianluca Serafini, Mario Amore, Guido Bondolfi, and et al. 2020. Suicidality Assessment of the Elderly With Physical Illness in the Emergency Department. Frontiers in Psychiatry 11: 558974. [CrossRef] [PubMed]

Dearing, Ronda L., Jeffrey Stuewig, and June Price Tangney. 2005. On the importance of distinguishing shame from guilt: Relations to problematic alcohol and drug use. Addictive Behaviors 30: 1392-404. [CrossRef]

Durkheim, Émile. 1951. Suicide. New York: Free Press. First published 1897.

Gearing, Robin Edward, and Dana Alonzo. 2018. Religion and Suicide: New Findings. Journal of Religion and Health 57: 2478-99. [CrossRef] [PubMed]

Goodwill, Janelle R., and Sasha Zhu. 2020. Association between perceived public stigma and suicidal behaviors among college students of color in the U.S. Journal of Affective Disorders 1: 1-7. [CrossRef] [PubMed]

Greeley, Andrew. 1989. Protestant and Catholic: Is the analogical imagination extinct? American Sociological Review 54: 485-502. [CrossRef]

Hegedûs, Rita. 2019. Az öngyilkossággal kapcsolatos attitúdök vizsgálata [A study of attitudes toward suicide]. In Az öngyilkosság szociológiája. [Sociology of Suicide]. Edited by Zonda Tamás, Károly Bozsonyi and Ferenc Moksony. Budapest: Károli Gáspár Református Egyetem - L'Harmattan Kiadó, pp. 151-62.

Kane, Jeremy C., Melissa A. Elafros, Sarah M. Murray, Ellen M. H. Mitchell, Jura L. Augustinavicius, Sara Causevic, and Stefan D. Bara. 2019. A scoping review of health-related stigma outcomes for high-burden diseases in low- and middle-income countries. BMC Medicine 17: 17. [CrossRef]

Lawrence, Ryan E., Maria A. Oquendo, Barbara Stanley Oquendo, and Barbara Stanley. 2016. Religion and suicide risk: A systematic review. Archives of Suicide Research 20: 1-21. [CrossRef] [PubMed]

Lewis, Helen Block. 1971. Shame and Guilt in Neurosis. New York: International Universities Press.

Lizardi, Dana, Kanita Dervic, Michael F. Grunebaum, Ainsley K. Burke, J. John Mann, and Maria A. Oquendo. 2008. The role of moral objections to suicide in the assessment of suicidal patients. Journal of Psychiatric Research 42: 815-21. [CrossRef] [PubMed]

Mason, Karen. 2021. Suicide Stigma in Christian Faith Communities: A Qualitative Study. Religions 12: 540. [CrossRef]

Moksony, Ferenc. 1998. Attitudes toward suicide in Hungary: Is there a regional subculture of self-destruction? Paper presented at the European Symposium on Suicide and Suicidal Behavior, Gent, Belgium, September 9-12.

Moksony, Ferenc, and Rita Hegedús. 2019. Religion and suicide: How culture modifies the effect of social integration. Archives of Suicide Research 23: 151-62. [CrossRef]

Mueller, Anna S., and Seth Abrutyn. 2016. Adolescents under pressure: A new Durkheimian framework for understanding adolescent suicide in a cohesive community. American Sociological Review 81: 1-23. [CrossRef]

Mueller, Anna S., Seth Abrutyn, and Cynthia Stockton. 2015. Can social ties be harmful? Examining the spread of suicide in early adulthood. Sociological Perspectives 58: 204-22. [CrossRef] [PubMed]

Pescosolido, Bernice A. 1994. Bringing Durkheim into the 21st century: A social network approach to unresolved issues in the study of suicide. In Emile Durkheim: Le Suicide-100 Years Later. Edited by David Lester. Philadelphia: The Charles Press, pp. $264-95$.

Reynders, Alexandre, Ad J. F. M Kerkhof, Geert Molenberghs, and Chantal Van Audenhove. 2015. Help-seeking, stigma and attitudes of people with and without a suicidal past. A comparison between a low and a high suicide rate country. Journal of Affective Disorders 178: 5-11. [CrossRef] [PubMed]

Rimkeviciene, Jurgita, Jacinta Hawgood, John O'Gorman, and Diego De Leo. 2015. Personal stigma in suicide attempters. Death Studies 39: 592-99. [CrossRef] [PubMed] 
Rüsch, Nicolas, Patrick W. Corrigan, Andrew R. Todd, and Galen V. Bodenhausen. 2010. Implicit self-Stigma in people with mental illness. Journal of Nervous and Mental Disease 198: 150-53. [CrossRef]

Schomerus, Georg, Charlotte Auer, Dieter Rhode, Melanie Luppa, Harald J Freyberger, and Silke Schmidt. 2010. Personal stigma, problem appraisal and perceived need for professional help in currently untreated depressed persons. Journal of Affective Disorders 139: 94-97. [CrossRef]

Schomerus, Georg, Sara Evans-Lacko, Nicolas Rüsch, Ramin Mojtabai, Matthias Claus Angermeyer, and Graham Thornicroft. 2014. Collective levels of stigma and national suicide rates in 25 European countries. Epidemiology and Psychiatric Sciences 24: 166-71. [CrossRef]

Schwadel, Philip, and Christina D. Falci. 2012. Interactive effects of church attendance and religious tradition on depressive symptoms and positive affect. Society and Mental Health 2: 21-34. [CrossRef]

Simonsen, Carmen, Sofie R. Aminoff, Anja Vaskinn, Elizabeth A. Barrett, Ann Faerden, Torill Ueland, Ole A. Andreassen, Kristin Lie Romm, and Ingrid Melle. 2019. Perceived and experienced stigma in first-episode psychosis: A 1-year follow-up study. Comprehensive Psychiatry 95: 152134. [CrossRef]

Stack, Steven, and Augustine J. Kposowa. 2011. Religion and suicide acceptability: A cross-national analysis. Journal for the Scientific Study of Religion 50: 289-306. [CrossRef]

Stangl, Anne L., Valerie A. Earnshaw, Carmen H. Logie, Wim van Brakel, Leickness C. Simbayi, Iman Barré, and John F. Dovidio. 2019. The Health Stigma and Discrimination Framework: A global, crosscutting framework to inform research, intervention development, and policy on health-related stigmas. BMC Medicine 17: 31. [CrossRef]

Stuber, Jennifer, Ilan Meyer, and Bruce Link. 2008. Stigma, prejudice, discrimination and health. Social Science E Medicine 67: 351. [CrossRef]

Sudak, Howard, Karen Maxim, and Maryellen Carpenter. 2008. Suicide and stigma: A review of the literature and personal reflections. Academic Psychiatry 32: 136-42. [CrossRef]

Tangney, June P., Rowland S. Flicker, Laura Barlow, and Deborah Hill. 1996. Are shame, guilt, and embarrassment distinct emotions? Journal of Personality and Social Psychology 70: 1256-69. [CrossRef]

Thornicroft, Graham, Elaine Brohan, Diana Rose, Norman Sartorius, Morven Leese, and INDIGO Study Group. 2009. Global pattern of experienced and anticipated discrimination against people with schizophrenia: A cross-sectional survey. Lancet 3739661: 408-15. [CrossRef]

Tomcsányi, Teodóra. 2003. Bún, bűntudat, szégyen. [Guilt, sense of guilt, and shame]. In Valláspszichológiai Tanulmányok. [Studies in the Psychology of Religion]. Edited by Katalin Horváth-Szabó. Budapest: Akadémiai Kiadó, pp. 153-86.

Torgler, Benno, and Christoph Schaltegger. 2014. Suicide and religion: New evidence on the differences between Protestantism and Catholicism. Journal for the Scientific Study of Religion 53: 316-40. [CrossRef]

van den Brink, Bart, Hanneke Schaap, and Arjan W. Braam. 2018. Moral objections and fear of hell: An important barrier to suicidality. Journal of Religion and Health 57: 2301-12. [CrossRef] [PubMed] 